\title{
Proteomic Analysis of Saliva in HIV-Positive Heroin Addicts Reveals Proteins Correlated with Cognition
}

\author{
Stephen S. Dominy ${ }^{1 * 9}$, Joseph N. Brown ${ }^{29}$, Mark I. Ryder ${ }^{3}$, Marina Gritsenko ${ }^{2}$, Jon M. Jacobs ${ }^{2}$, \\ Richard D. Smith ${ }^{2 *}$
}

1 Department of Psychiatry, University of California San Francisco, San Francisco, California, United States of America, 2 Biological Sciences Division, Pacific Northwest National Laboratories, Richland, Washington, United States of America, 3 Division of Periodontology, Department of Orofacial Sciences, University of California San Francisco, San Francisco, California, United States of America

\begin{abstract}
The prevalence of HIV-associated neurocognitive disorders (HAND) remains high despite effective antiretroviral therapies. Multiple etiologies have been proposed over the last several years to account for this phenomenon, including the neurotoxic effects of antiretrovirals and co-morbid substance abuse; however, no underlying molecular mechanism has been identified. Emerging evidence in several fields has linked the gut to brain diseases, but the effect of the gut on the brain during HIV infection has not been explored. Saliva is the most accessible gut biofluid, and is therefore of great scientific interest for diagnostic and prognostic purposes. This study presents a longitudinal, liquid chromatography-mass spectrometry-based quantitative proteomics study investigating saliva samples taken from 8 HIV-positive (HIV ${ }^{+}$), 11 - negative ( $\mathrm{HIV}^{-}$) heroin addicts. In addition, saliva samples were investigated from $11 \mathrm{HIV}^{-}$, non-heroin addicted healthy controls. In the $\mathrm{HIV}^{+}$group, 58 proteins were identified that show significant correlations with cognitive scores, implicating disruption of protein quality control pathways by HIV. Notably, only one protein from the $\mathrm{HIV}^{-}$heroin addict cohort showed a significant correlation with cognitive scores, and no proteins correlated with cognitive scores in the healthy control group. In addition, the majority of correlated proteins have been shown to be associated with exosomes, allowing us to propose that the salivary glands and/or oral epithelium may modulate brain function during HIV infection through the release of discrete packets of proteins in the form of exosomes.
\end{abstract}

Citation: Dominy SS, Brown JN, Ryder MI, Gritsenko M, Jacobs JM, et al. (2014) Proteomic Analysis of Saliva in HIV-Positive Heroin Addicts Reveals Proteins Correlated with Cognition. PLoS ONE 9(4): e89366. doi:10.1371/journal.pone.0089366

Editor: Ulrike Schmidt, Max Planck Institute of Psychiatry, Germany

Received August 29, 2013; Accepted January 21, 2014; Published April 9, 2014

Copyright: (C) 2014 Dominy et al. This is an open-access article distributed under the terms of the Creative Commons Attribution License, which permits unrestricted use, distribution, and reproduction in any medium, provided the original author and source are credited.

Funding: The majority of the research was funded through $\mathrm{NIH}$ grant P01 DA026134, including proteomics measurements from capabilities developed at PNNL under NIH grant P41GM103493. The IL1RA ELISA research was supported by a grant from the National Institutes of Health, University of California, San Francisco-Gladstone Institute of Virology and Immunology Center for AIDS Research, P30-AI027763. The funders had no role in study design, data collection and analysis, decision to publish, or preparation of the manuscript.

Competing Interests: The authors have declared that no competing interests exist.

* E-mail: stephen.dominy@ucsf.edu (SD); rds@pnnl.gov (RS)

9 These authors contributed equally to this work.

\section{Introduction}

HIV-associated neurocognitive disorders (HAND) remain common, even among patients receiving combination antiretroviral therapy (cART) [1]. The mechanisms underlying HAND remain elusive, but a history of a low nadir $\mathrm{CD} 4^{+}$count has been shown to be a strong predictor of cognitive impairment before and after the cART era [1,2]. In addition, it has been proposed that heroin and other illicit drugs are cofactors in HAND [3]. One area that has not been investigated in relation to HAND is the influence of the gut and associated microbiome on neurocognition. Evidence has emerged over the last decade that gut immune, neural, and enteroendocrine mechanisms as well as soluble factors or metabolites of gut commensal bacteria may influence the brain [4-7]. However, the specific pathways and molecules underlying communication between the gut and brain are poorly understood. An enhanced understanding of gut proteins, both human and microbial, underlying gut-brain interactions during HIV infection in heroin addicted persons may provide novel insights into HAND in this population. This study focused on human proteins in saliva and their relationship to cognition, as saliva is one of the most clinically accessible gut biofluids, and accumulating evidence suggests that the study of salivary proteins may provide insight into the pathophysiological mechanisms of neurodegenerative diseases [8-12]. Previous proteomic studies of cognition in HIV disease have analyzed cerebrospinal fluid (CSF) $[13,14]$, serum $[15,16]$, macrophage secretions [17], and brain tissue [18,19] in nonheroin addicted subjects. Rozek et al. identified twenty differentially expressed proteins in $\mathrm{CSF}$ of $\mathrm{HIV}^{+}$subjects with and without HIV-associated dementia (HAD), including six proteins they validated by western blot analysis (cystatin $\mathrm{C}$, gelsolin, complement $\mathrm{C} 3$, clusterin, vitamin D-binding protein, and procollagen- $\mathrm{C}$ -endopeptidase enhancer 1) [13]. Laspiur et al. identified a set of CSF proteins associated with cognitive impairment in HIV disease that included soluble superoxide dismutase (SOD 1), migration inhibitory factor (MIF)-related protein 14, macrophage capping protein, neurosecretory protein VGF, galactein-7, L-plastin, acylphosphatase 1 , and tyrosine 3/tryptophan 5-monoxygenase activation protein [14]. Proteomic analysis of serum in HAD by Wiederin et al. revealed gelsolin and prealbumin as differentially 
expressed proteins [15]. A novel study by Toro-Nieves et al. analyzed proteomes of macrophages infected by HIV-1 viral strains from $\mathrm{HIV}^{+}$women with cognitive impairment or normal cognition. Toro-Nieves' group found distinct changes in macrophage proteins between the two conditions, with macrophages infected with HIV-1 strains from the cognitively impaired subjects demonstrating changes in proteins related to apoptosis, chemotaxis, inflammation, and redox metabolism [17].

In the first proteomic study to examine autopsied brain tissue from subjects with HAD and subjects with HIV infection but without dementia, Zhou et al. found a significant alteration of 31 proteins in HAD subjects' brain tissue compared to the nondemented, HIV-infected subjects, with $90 \%$ of the altered proteins overlapping with proteins previously identified in non-viral neurodegenerative disorders [18]. Zhou's team validated four of the altered proteins (carbonic anhydrase 2, glutamine synthetase, creatine kinase ubiquitous mitochondrial, dihydropyrimidinaserelated protein 2) in brain tissue using Western blotting and immunohistochemistry [18]. Gelman and Nguyen conducted a postmortem proteomic analysis of human frontal neocortex synaptosomes from $\mathrm{HIV}$-infected subjects and found altered concentrations of synapsin 1b, 14-3-3 zeta, 14-3-3 epsilon, and stathmin in the nerve endings, which the authors suggested supports an HIV-induced disruption of the ubiquitin-proteasome system (UPS), the physiological regulator of protein quality control in the synaptic compartment [19].

Disruption of the UPS in synapses has also been demonstrated for drugs of abuse. Stockton and Devi recently conducted a review of proteomic studies looking at the morphine-dependent synapse, and found morphine consistently induces significant changes in proteins in the UPS, with heat shock and heat shock-related proteins over represented in neuroproteomic studies of morphine [20]. Wang et al. recently reviewed proteomic studies of addictive drugs and noted 497 proteins that have been associated with drug exposure, including many proteins involved in synaptic transmission and signaling pathways [21]. Recently, Brown et al. administered morphine to two species of nonhuman primates over a 20-day period and measured protein changes in inguinal lymph node, colon, peripheral blood, and CSF [22]. Morphine exposure resulted in altered protein expression in all tissues examined in both species, with a significant alteration of the expression of 107 proteins in the CSF of African green monkeys, and 17 proteins in the CSF of pigtailed macaques. Functional categories of CSF proteins altered by morphine in the NHPs included immune response, cell growth, transport, energy metabolism, and signal transduction [22]. In human opiate addicts, Zill et al. performed postmortem proteomic analysis on brain tissue from the amygdala and found alterations in the expression of beta-tubulin and heat-shock protein HSP60 when compared to controls [23].

Drug-induced changes in protein expression may be responsible, in part, for the finding that drug addiction can lead to cognitive deficits across multiple domains, especially cognitive function related to frontal-striatal circuitry [24]. Heroin addiction in particular has been linked to gray matter deficits [25-27] and accelerated brain aging [28]. Methadone, an opioid treatment for heroin addiction, has also been associated with impaired cognitive function [29-31]. Despite these well-recognized negative effects of drugs on cognition, Byrd et al. recently demonstrated that the cognitive effects of HIV can be isolated in drug-addicted, HIVinfected cohorts [24].

We were thus motivated to take a prospective, longitudinal, and unbiased approach using proteomics to discover correlations that might exist between human salivary proteins and cognition in
$\mathrm{HIV}^{+}$and $\mathrm{HIV}^{-}$heroin addicts during the initial phases of methadone treatment, and to use a group of healthy, $\mathrm{HIV}^{-}$, nonaddicted subjects as a control. The focus of our study was to investigate a set of fundamental questions concerning salivary protein abundances and their correlation with cognition, particularly in the context of heroin and polydrug use in $\mathrm{HIV}^{+}$and $\mathrm{HIV}^{-}$subjects. The approach undertaken involved submitting serial saliva samples to high mass accuracy and high throughput liquid chromatography based mass spectrometry (LC-MS/MS), which would allow, within subjects, an unbiased view of the proteins shed/secreted into this clinical biofluid and allow correlational analyses between salivary protein abundances and serial cognitive scores as measured by the Digit Symbol Substitution Test (DSST) [32,33]. The overall driving analytical questions include, what, if any, correlations can be seen between the abundance of specific salivary proteins and DSST scores in $\mathrm{HIV}^{+}$or $\mathrm{HIV}^{-}$heroin addicts, how these proteins are related longitudinally to methadone treatment and HIV status, and can any of these identified proteins be used as potential indicators of neurodegenerative disease mechanisms.

\section{Materials and Methods}

\section{Ethics Statement}

The study was approved by the University of California Committee on Human Research and each participant provided voluntary written informed consent.

\section{Research Participants}

Participants were drawn from the methadone maintenance clinic at San Francisco General Hospital upon presentation for treatment of heroin addiction. Eight participants were $\mathrm{HIV}^{+}$and eleven participants were $\mathrm{HIV}^{-}$. Healthy, non-addicted $\mathrm{HIV}^{-}$ participants $(n=11)$ were drawn from a control group for a drug interaction study [34]. Table 1 presents data on demographic characteristics for all study participants. There were significantly more women among the $\mathrm{HIV}^{-}$subjects relative to the $\mathrm{HIV}^{+}$ subjects, and the $\mathrm{HIV}^{-}$subjects were using significantly more methamphetamine/amphetamine than $\mathrm{HIV}^{+}$subjects.

\section{Serial Saliva Sample Collection and Cognitive Testing}

Saliva samples were collected by having participants chew on a small square of Parafilm ${ }^{\circledR}$ (Menasha, WI) for five minutes or less and spit into a sterile collection cup. Saliva samples were then aliquoted and frozen at $-80^{\circ} \mathrm{C}$ until time of analysis. Saliva sample collection and cognitive testing with the 2-minute computerized version of the DSST [35] were performed concurrently on five separate occasions; the first sampling session occurred on day 1 when the participant first presented to the methadone clinic and before the participant received their first dose of methadone; the second and third sampling sessions occurred on average on days 35 and 36, respectively; and the fourth and fifth sampling sessions occurred on average on days 100 and 102, respectively. All samples were processed individually, and a minimal number of time points were missed by some participants. For the control group, saliva sampling and cognitive testing with the DSST were performed on two separate occasions separated by a period of 15 days. The computerized version of the DSST asks subjects to match symbols with their corresponding digit within a two minute time limit. The number of correct responses within the two minute time limit is a measure of executive cognitive functioning, working memory, processing speed, and visuo-spatial attention [36]. There is not an agreedupon threshold for normality for the DSST score, but lower DSST 
Table 1. Demographics.

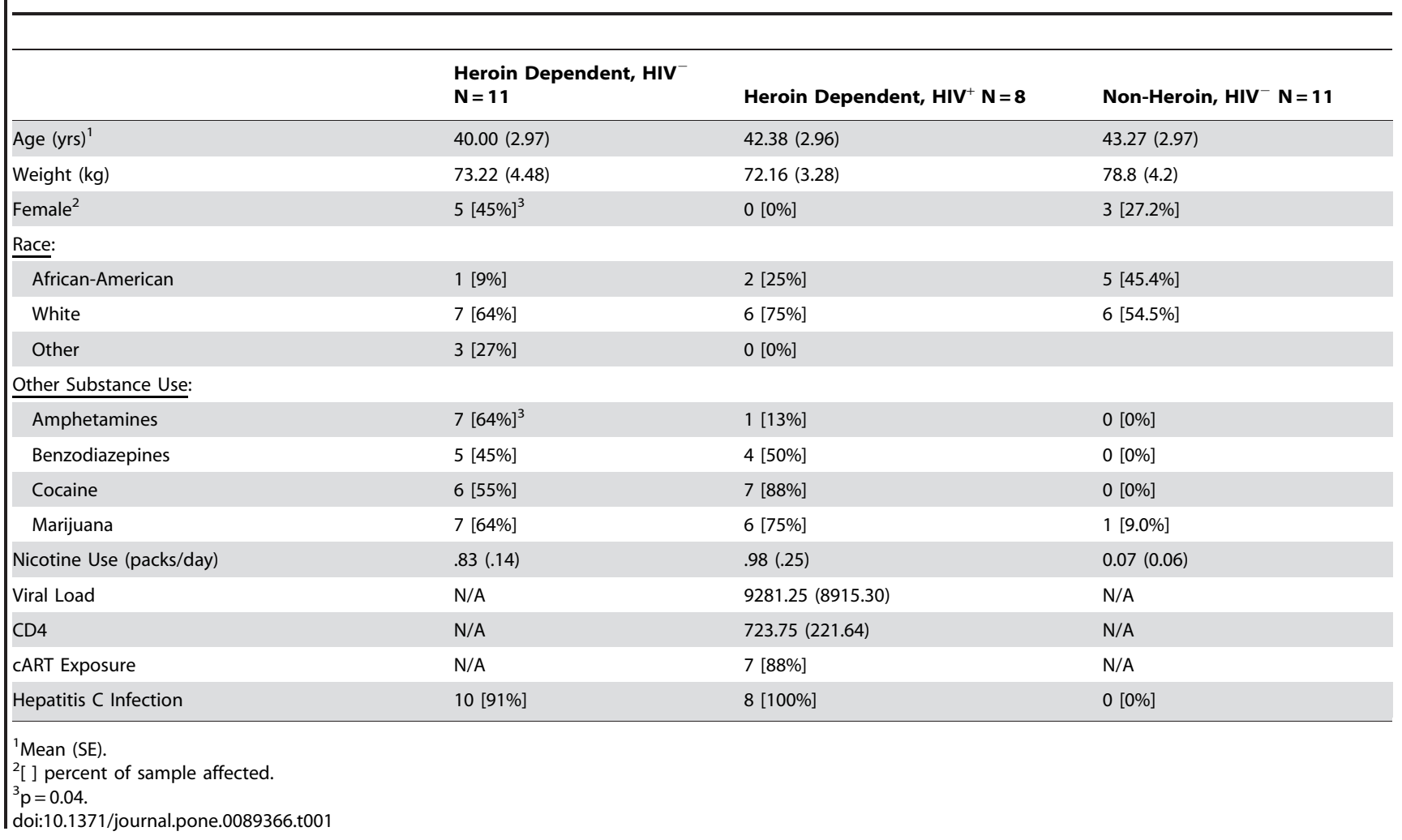

scores indicate worse performance [36]. At each sampling time point, urine was tested for recent use of illicit opioids, cocaine, amphetamines, benzodiazepines, and marijuana.

ELISA analyses. Samples were prepared for ELISA analysis by removing mucin precipitate and other particulate matter by centrifuging samples at $1500 \times g$ for $15 \mathrm{~min}$. A commercially available IL1RA ELISA kit (R\&D Systems DRA-00B) was used to measure the concentration of IL1RA samples in saliva from $\mathrm{HIV}^{+}$ subjects. The protocol supplied with the ELISA kit was followed, except that Saliva Matrix (Salimetrics LLC, 3-3000) was used as a diluent in place of the kit-provided assay diluents to better normalize the protein antibody binding conditions for saliva samples.

Sample preparation for proteome analysis. Saliva samples were denatured with the addition of solid urea to a final concentration of $8 \mathrm{M}$. Protein concentration was determined by bicinchoninic acid assay (Pierce Biotechnology, Inc., Rockford, IL, USA). To enhance proteolysis, samples were reduced with $10 \mathrm{mM}$ DTT for 1 hour at $37^{\circ} \mathrm{C}$. For trypsin digestion, samples were

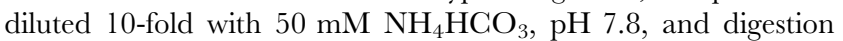
was performed with sequencing grade-modified porcine trypsin prepared according to the manufacturer (Promega, Madison, WI, USA). Saliva proteins were digested at 1:50 (wt/wt) trypsin-toprotein ratio for 3 hours at $37^{\circ} \mathrm{C}$, and desalted by solid-phase extraction (Discovery DSC-18, SUPELCO, Bellefonte, PA). Peptides were eluted from the SPE column using $80 \%$ acetonitrile with $0.1 \%$ trifluoroacetic acid, and dried in Speed-Vac SC 250 Express (Thermo Savant, Holbrook, NY).

RPLC separation and MS(/MS) acquisition. The method used in this study, with the coupling of a constant-pressure $(5,000-$ $\mathrm{lb} / \mathrm{in}^{2}$ ) reversed-phase capillary liquid chromatography (RPLC) system $(75-\mu \mathrm{m}$ inside diameter, $360-\mu \mathrm{m}$ outside diameter, $65-\mathrm{cm}$ capillary; Polymicro Technologies Inc., Phoenix, AZ, USA) and a
Velos LTQ-Orbitrap mass spectrometer (MS; Thermo Scientific, Waltham, MA, USA) using an electrospray ionization source manufactured in-house, has been previously reported [37-39]. The instrument was operated in data-dependent mode with an $\mathrm{m} /$ $\mathrm{z}$ range of 400-2000. The 10 most abundant ions from the MS analysis were selected for MS/MS analysis using a normalized collision energy setting of $35 \%$. A dynamic exclusion of 1 min was used to avoid repetitive analysis of the same abundant precursor ion. The heated capillary was maintained at $200^{\circ} \mathrm{C}$, and the ESI voltage was held at $2.2 \mathrm{kV}$ [37-39].

Mass spectrometry data analysis. The LC-MS/MS raw data were converted into a .dta file using an in-house software, DeconMSn (version v2.1.4.1), which accurately calculates the parent monoisotopic mass for each spectrum from the parent isotopic distribution using a modified THRASH approach. The SEQUEST software ((Version v.27, Rev 12, Thermo Fisher Scientific, Waltham MA)) was used to search the MS/MS spectral data against human UniProt fasta file containing 20,276 protein sequences, downloaded May 5, 2011. Porcine trypsin was added into the database as an expected contaminant. No cleavage specificity was defined in the database searching. For AMT tag database creation, raw SEQUEST results were filtered on: (1) Xcorr $\geq 1.9$ for charge state +1 , (2) Xcorr $\geq 2.2$ for charge state +2 , and (3) 3.75 for charge state +3 , using 3.0 and 1.0 Da for parent and fragment ion tolerances, respectively. High resolution LC-MS features were deconvoluted by Decon2Ls (version 1.0.2, using default parameters) and aligned to the mass and time tag database using VIPER (version 3.45 using default parameters) using the theoretical mass and observed normalized elution times (NET) for each peptide. This approach to proteomics research is enabled by a number of both published [40-44] and unpublished in-group development tools that are freely available for download at http://omics.pnl.gov. Peptide alignment results were further 
refined with a $\mathrm{FDR}<5 \%$ based on STAC and uniqueness probability measurements [45], mass error $<2 \mathrm{ppm}$, and peptide identifications were filtered using a MSGF score $<1 \mathrm{E}-10$ [46].

\section{Statistical analysis}

All statistical analyses were performed with the $\mathrm{R}$ software framework [47]. Peptide relative abundance values were $\log _{2}$ transformed and used for an ANOVA analysis within DanteR [48](http://omics.pnl.gov). Relative protein abundance was estimated by using median peptide intensity values [49], requiring a minimum of 2 unique peptides. Pearson product-moment correlations were performed to determine the strength of linear dependence between DSST scores and relative protein abundances. $P$ values from ANOVA and Pearson correlation analyses were corrected for multiple tests using the Benjamini-Hochberg adjustment [50]. Proteins were considered to have shown a significant change in salivary abundance with $P \leq 0.05$.

\section{Results}

The objective of this study is to determine if significant correlations exist between the abundance of specific salivary proteins and DSST cognitive scores from $\mathrm{HIV}^{+}$or $\mathrm{HIV}^{-}$ individuals receiving treatment for heroin addiction. The proteomic profile of eight $\mathrm{HIV}^{+}$, and eleven $\mathrm{HIV}^{-}$heroin dependent subjects (at five longitudinal time points) were included, along with $11 \mathrm{HIV}^{-}$, non-heroin dependent subjects as controls (at two time points), see Table 1 and Figure 1A. Starting at day 0, heroin dependent subjects initiated methadone treatment, which continued throughout the study. Across all five time points during the course of the study, whole saliva was collected for proteomic analysis and a DSST score of cognition was determined (See Table S1). LC-MS/MS analyses and label-free quantitative data analysis (see materials and methods for details) identified and quantified the abundance of 472 salivary proteins in the $\mathrm{HIV}^{-}$group, 483 proteins in the $\mathrm{HIV}^{+}$group, and 493 proteins in the $\mathrm{HIV}^{-}$, heroin independent group, see Figure 1B and Tables S2,S3. Correlation of DSST scores with each individual protein value revealed only a single significant protein correlation in the $\mathrm{HIV}^{-}$group, in contrast to 58 significant protein correlations in the $\mathrm{HIV}^{+}$group $(P<0.05)$ (Table 2). No significant DSST score/saliva protein correlation was observed in the $\mathrm{HIV}^{-}$, heroin independent control group. Table S4 provides the overlap of salivary proteins from our current study that correlate with DSST scores and proteins that have been shown by other investigators to be modulated by morphine and other drugs of abuse. In addition, Table S5 provides the overlap of salivary proteins with correlations of DSST scores and proteins identified in prior proteomic studies related to HIV infection.

\section{Proteins Involved in Protein Quality Control Have Positive Correlations with Cognitive Scores}

Multiple saliva proteins of interest were observed to have a correlative relationship with DSST scores, specifically, a significant positive correlation was determined between salivary valosincontaining protein (VCP, aka TERA/p97/Cdc48) and DSST scores $(\mathrm{r}=0.53$ and $P=0.014)$, see Figure 2 , in $\mathrm{HIV}^{+}$heroin addicts. VCP is a key component in the cytosolic degradation of proteins by the proteasome and it also plays a key role in autophagy [51]. One of the main functions of VCP involves the disassembly of protein complexes and aggregates by extracting ubiquitinated proteins from both the endoplasmic reticulum and the outer mitochondrial membrane and presenting the ubiquitintagged proteins to the proteasome for degradation [51-53].
Disruption of this pathway has been found to lead to excessive accumulation of ubiquitinated proteins and cellular and mitochondrial dysfunction [53]. Watts et al. found that mutations in the VCP gene result in the autosomal-dominant degenerative disease known as Inclusion Body Myositis with Paget's disease of the bone and Frontotemporal Dementia [54]. VCP has also been linked to Huntington's disease, Parkinson's disease, amyotrophic lateral sclerosis, and Alzheimer's disease $[51,52,55]$. Of note, Jager et al. recently demonstrated a direct protein-protein interaction between HIV gp4l and VCP [56].

Salivary ubiquitin-like modifier-activating enzyme 1 (UBAl, aka UBE1) was also observed with a significant positive correlation with cognitive scores, as measured by the DSST, in $\mathrm{HIV}^{+}$heroin addicts $(\mathrm{r}=0.47$ and $P=0.036$ ) (Figure 2). UBAl is critical for protein quality control since it is involved in the first step of activating ubiquitin to mark damaged proteins for degradation by the proteasome [57]. Mutations in the UBAl gene have been found to alter the ubiquitin-proteasome system resulting in an early-onset, fatal neurodegenerative disorder involving lower motor neurons in childhood [58]. Jager's group has demonstrated a direct protein-protein interaction between UBAl and the HIV integrase protein [56].

A third protein critically involved in protein quality control that was found to be significantly correlated with DSST scores is calnexin $(\mathrm{CANX})(\mathrm{r}=0.74, P=9.96 \mathrm{E}-05)$ (Figure 2). Calnexin is a transmembrane chaperone of the endoplasmic reticulum that ensures the proper folding and quality control of newly synthesized glycoproteins $[59,60]$. In vitro studies have demonstrated that calnexin may be important in protecting against neurotoxicity associated with misfolded proteins [61]. HIV gp160 has been shown to have a direct protein-protein interaction with calnexin $[56,62]$.

\section{Interleukin-1 Receptor Antagonist Has a Negative Correlation with Cognitive Scores}

Strikingly, only one salivary protein demonstrated a significant negative correlation with DSST scores, IL-1 receptor antagonist (IL1RA) (r=-0.57, $P=0.009$ ) (Figure 1). IL1RA is a naturally occurring antagonist of IL-1 that is capable of blocking IL-1 effects by binding to its receptor [63]. HIV has been shown to induce an excessive abundance of IL1RA when compared to IL-1 in human primary monocytes in vitro. Zavala et al. demonstrated that HIV triggered IL1RA in a mean 1,000-fold increase over IL- $1 \alpha \beta$, a ratio 20 -fold higher than that obtained with lipopolysaccharide [64]. IL1RA is associated with several neurodegenerative disorders (see Discussion below).

\section{Detection of Salivary IL1RA by ELISA}

For the reasons described above and to demonstrate that the inverse relationship between IL1RA and DSST can be detected by alternative quantitative strategies, this receptor antagonist was selected for targeted analysis by ELISA. IL1RA concentrations, which ranged from $290 \mathrm{ng} / \mathrm{ml}$ to $>1 \mu \mathrm{g} / \mathrm{ml}$, were measured in 6 $\mathrm{HIV}^{+}$individuals across 4 time points during the study. Similar to the LS-MS/MS results, DSST scores and the absolute concentrations of IL1RA demonstrate an inverse correlation; see Figure 3, further supporting initial quantitative observations by LC-MS/ MS.

\section{Heat Shock Response Proteins are Positively Correlated with Cognitive Scores}

Significant positive correlations between protein abundance and DSST scores were identified with 4 important heat shock proteins: 


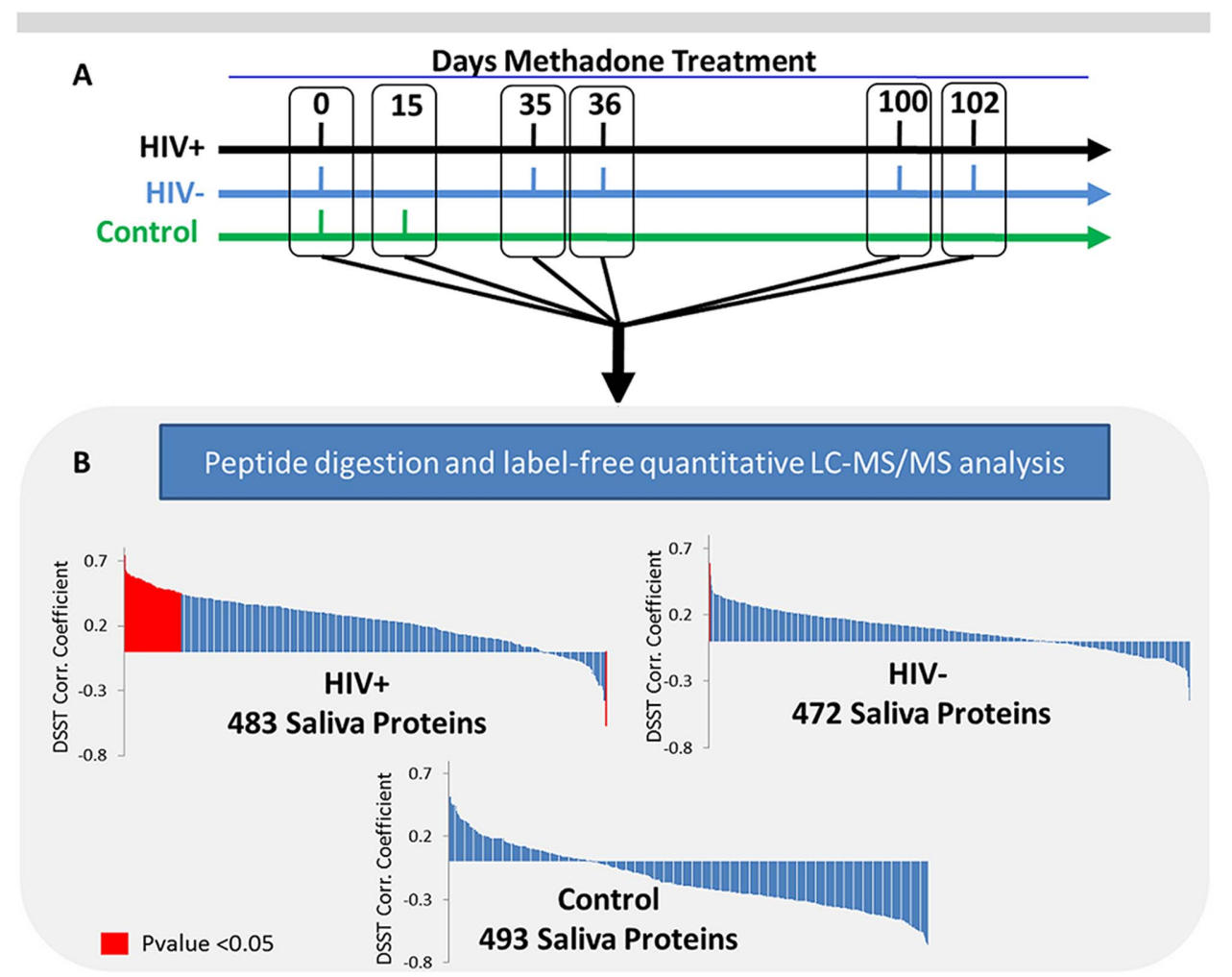

Figure 1. Overview of clinical saliva sample collection and proteomic analysis. A) Timeline of the three participant cohorts and their respective days of saliva sample collection and DSST testing. The control population was HIV $^{-}$and heroin independent so no methadone treatment was initiated at day 0. B) Graph of DSST correlation with all identified and quantified saliva proteins from each respective group after sample collection, processing, instrument and data analysis. Proteins shown in red are those which pass the Benjamini-Hochberg corrected $P$-value of $<0.05$. doi:10.1371/journal.pone.0089366.g001

heat shock $70 \mathrm{kDa}$ protein $1 \mathrm{~A} / 1 \mathrm{~B}(\mathrm{HSPAlA})(\mathrm{r}=0.6, P=0.008)$, heat shock protein HSP 90-alpha (HSP90AAl) $(\mathrm{r}=0.53$, $P=0.014)$, alpha-crystallin B chain (CRYAB/HSPB5) $(\mathrm{r}=0.47$, $P=0.036)$, and heat shock protein HSP 90-beta (HSP90AB1)(r=0.46, $P=0.040)$ (Table 2). The heat shock protein response is a highly conserved physiologic mechanism that protects cells against the cytotoxic effects of protein aggregation [65]. Heat shock proteins are molecular chaperones that assist in the folding of misfolded proteins, preventing their aggregation [66-69]. The Hsp90 paralogues, HSP90AAl and HSP90AB1, occupy central positions in protein homeostasis [70,71].

\section{Differential Saliva Protein Abundances due to Methadone Treatment}

Due to the longitudinal nature of the study, we performed a comparative statistical analysis of the overall saliva protein abundance differences observed due to methadone treatment for both $\mathrm{HIV}^{+}$and $\mathrm{HIV}^{-}$individuals. Comparisons were made between time point 0 (time of first treatment) and 35/36 days into treatment, see Figure $4 \mathrm{~A}$ and $4 \mathrm{~B}$. These sampling points provided the most direct comparison for determining a methadone treatment effect. 91 and 69 saliva proteins were observed as differentially abundant across the $\mathrm{HIV}^{+}$and $\mathrm{HIV}^{-}$individuals respectively (see table S6). The overlap between each saliva protein subset and those proteins previously observed as correlative with DSST scores is shown in Figure 4C. Initial observations include a somewhat more homogenous set of differential proteins apparent in the $\mathrm{HIV}^{+}$subset compared to the $\mathrm{HIV}^{-}$cohort, and interestingly a minimal overlap with DSST correlative proteins.
Based upon such observations, we can now preliminarily discriminate those protein abundance changes which are likely to be dependent or independent (to some extent) of HIV status and/or methadone treatment. Both VCP and Calnexin overlap with methadone treatment protein changes and would appear to be sensitive to such perturbations, but only in the $\mathrm{HIV}^{+}$set, while IL1RA, UBA1, and all altered heat shock proteins do not overlap and appear to be unrelated to methadone treatment effects. Additionally, since there was no change in HIV status within this timeframe, we would not necessarily expect a high overlap of DSST correlative proteins with the $\mathrm{HIV}^{+}$group, however proteins uniquely identified as differential between $\mathrm{HIV}^{+}$and $\mathrm{HIV}^{-}$ individuals are likely due to HIV status and/or cART treatment. Conversely, those 24 proteins $(21+3)$ which do overlap between $\mathrm{HIV}^{+}$and $\mathrm{HIV}^{-}$individuals can be viewed as saliva proteins changing independent of HIV status, and hence more related specifically to methadone treatment.

\section{Discussion}

Using a high mass accuracy LC-MS/MS based proteomic analysis, we found significant correlations between salivary proteins and DSST cognitive scores in $\mathrm{HIV}^{+}$heroin addicts. Importantly, we found only one correlation between salivary proteins and cognitive scores in $\mathrm{HIV}^{-}$heroin addicts, and no correlations in $\mathrm{HIV}^{-}$heroin independent individuals. Additionally, the effect of methadone treatment across both $\mathrm{HIV}^{+}$and HIV $^{-}$individuals informed upon the possible links of DSST correlative proteins to the sensitivity to methadone treatment. As noted above, the salivary proteins in $\mathrm{HIV}^{+}$heroin addicts that 
Table 2. Proteins showing a significant correlation between abundance and DSST score.

\begin{tabular}{|c|c|c|c|c|}
\hline UniProt & Name & Symbol & Corr & P-value \\
\hline P27824 & calnexin & CANX & 0.74 & $9.96 \mathrm{E}-05$ \\
\hline P61158 & ARP3 actin-related protein 3 homolog (yeast) & ACTR3 & 0.62 & 0.00705 \\
\hline Q13885 & tubulin, beta $2 \mathrm{~A}$ class Ila & TUBB2A & 0.61 & 0.00705 \\
\hline P16152 & carbonyl reductase 1 & CBR1 & 0.6 & 0.00841 \\
\hline P08107 & heat shock $70 \mathrm{kDa}$ protein $1 \mathrm{~A}$ & HSPA1A & 0.6 & 0.00841 \\
\hline Q13509 & tubulin, beta 3 class III & TUBB3 & 0.59 & 0.00912 \\
\hline P35579 & myosin, heavy chain 9, non-muscle & MYH9 & 0.58 & 0.00912 \\
\hline Q3ZCM7 & tubulin, beta 8 class VIII & TBB8 & 0.58 & 0.00912 \\
\hline O75083 & WD repeat domain 1 & WDR1 & 0.58 & 0.00912 \\
\hline P46940 & IQ motif containing GTPase activating protein 1 & IQGAP1 & 0.57 & 0.00912 \\
\hline Q14134 & tripartite motif containing 29 & TRIM29 & 0.57 & 0.00912 \\
\hline P07437 & tubulin, beta class I & TUBB & 0.57 & 0.00912 \\
\hline Q8TD99 & desmin & DES & 0.56 & 0.00912 \\
\hline A6NNZ2 & tubulin beta- 8 chain B & TBB8B & 0.56 & 0.00912 \\
\hline A6NKZ8 & putative tubulin beta chain-like protein & YI016 & 0.56 & 0.00912 \\
\hline P18510 & interleukin 1 receptor antagonist & IL1RA & -0.57 & 0.00912 \\
\hline P21333 & filamin A, alpha & FLNA & 0.56 & 0.00924 \\
\hline Q6PEY2 & tubulin, alpha $3 e$ & TUBA3E & 0.56 & 0.00924 \\
\hline Q96ML2 & vimentin & VIM & 0.55 & 0.00924 \\
\hline Q9H4B7 & tubulin, beta 1 class $\mathrm{VI}$ & TUBB1 & 0.54 & 0.0125 \\
\hline P60842 & eukaryotic translation initiation factor $4 \mathrm{~A} 1$ & EIF4A1 & 0.54 & 0.0128 \\
\hline P63244 & guanine nucleotide binding protein (G protein), beta polypeptide 2-like 1 & GNB2L1 & 0.54 & 0.0133 \\
\hline P11413 & glucose-6-phosphate dehydrogenase & G6PD & 0.53 & 0.0143 \\
\hline P07900 & heat shock protein 90 kDa alpha (cytosolic), class A member 1 & HSP90AA1 & 0.53 & 0.0143 \\
\hline Q9BYX7 & POTE ankyrin domain family, member I & POTEKP & 0.53 & 0.0143 \\
\hline P55072 & valosin containing protein & VCP & 0.53 & 0.0143 \\
\hline P15104 & glutamate-ammonia ligase & GLUL & 0.52 & 0.016 \\
\hline P14780 & matrix metallopeptidase 9 & MMP9 & 0.52 & 0.0162 \\
\hline P59998 & actin related protein $2 / 3$ complex, subunit $4,20 \mathrm{kDa}$ & ARPC4 & 0.51 & 0.0223 \\
\hline Q71U19 & $\mathrm{H} 2 \mathrm{~A}$ histone family, member $\mathrm{V}$ & H2AFV & 0.51 & 0.0223 \\
\hline P00491 & purine nucleoside phosphorylase & PNP & 0.5 & 0.0227 \\
\hline 015231 & zinc finger protein 185 (LIM domain) & ZNF185 & 0.5 & 0.0232 \\
\hline P80188 & lipocalin 2 & LCN2 & 0.5 & 0.0271 \\
\hline P62269 & ribosomal protein S18 & RPS18 & 0.49 & 0.0286 \\
\hline P17931 & lectin, galactoside-binding, soluble, 3 & LGALS3 & 0.49 & 0.0291 \\
\hline P35749 & myosin, heavy chain 11 , smooth muscle & MYH11 & 0.49 & 0.0291 \\
\hline Q9H882 & myosin-14 & MYH14 & 0.49 & 0.0291 \\
\hline P62244 & ribosomal protein S15a & RPS15A & 0.49 & 0.0303 \\
\hline P35580 & myosin, heavy chain 10 , non-muscle & MYH10 & 0.48 & 0.0309 \\
\hline P15153 & ras-related C3 botulinum toxin substrate 2 & $\mathrm{RAC2}$ & 0.48 & 0.031 \\
\hline P26641 & eukaryotic translation elongation factor $1 \mathrm{gamma}$ & EEF1G & 0.48 & 0.0327 \\
\hline P02042 & hemoglobin, delta & $\mathrm{HBD}$ & 0.48 & 0.0327 \\
\hline P05164 & myeloperoxidase & MPO & 0.48 & 0.0327 \\
\hline Q6S8J3 & POTE ankyrin domain family, member $\mathrm{E}$ & POTEE & 0.48 & 0.0327 \\
\hline O15145 & actin related protein $2 / 3$ complex, subunit $3,21 \mathrm{kDa}$ & ARPC3 & 0.48 & 0.0332 \\
\hline P02144 & myoglobin & MB & 0.47 & 0.0338 \\
\hline P43490 & nicotinamide phosphoribosyltransferase & NAMPT & 0.47 & 0.0338 \\
\hline P02511 & crystallin, alpha B & CRYAB & 0.47 & 0.0367 \\
\hline A5АЗЕ0 & POTE ankyrin domain family, member $F$ & POTEF & 0.47 & 0.0367 \\
\hline
\end{tabular}


Table 2. Cont.

\begin{tabular}{|c|c|c|c|c|}
\hline UniProt & Name & Symbol & Corr & P-value \\
\hline P29401 & transketolase & TKT & 0.47 & 0.0367 \\
\hline P22314 & ubiquitin-like modifier activating enzyme 1 & UBA1 & 0.47 & 0.0367 \\
\hline P30613 & pyruvate kinase, liver and RBC & PKLR & 0.46 & 0.0386 \\
\hline P12814 & actinin, alpha 1 & ACTN1 & 0.46 & 0.0406 \\
\hline P08238 & heat shock protein $90 \mathrm{kDa}$ alpha (cytosolic), class B member 1 & HSP90AB1 & 0.46 & 0.0406 \\
\hline Q549N7 & hemoglobin subunit beta & HBB & 0.45 & 0.0425 \\
\hline P19105 & myosin, light chain $12 \mathrm{~A}$, regulatory, non-sarcomeric & MYL12A & 0.45 & 0.0425 \\
\hline Q86Y46 & keratin 73 & KRT73 & 0.45 & 0.0449 \\
\hline P01877 & Ig alpha- 2 chain $C$ region & IGHA2 & 0.45 & 0.0467 \\
\hline
\end{tabular}

doi:10.1371/journal.pone.0089366.t002

correlate with cognitive scores implicate molecular mechanisms involved in protein quality control and neurodegenerative diseases. Our proteomic results support Kragh et al.'s recent suggestion that defective protein quality control underlies HAND pathogenesis [72]. Kragh's group proposed that protein quality control could be disrupted if HIV proteins bound directly to components of the protein quality control machinery [72]. Jager et al. recently demonstrated that HIV proteins do bind directly to components of the protein quality control machinery, including VCP, UBAl, and CANX, proteins that we observed in the saliva of $\mathrm{HIV}^{+}$heroin addicts to have significant correlations with cognitive scores [56] (Table 2). Additional evidence of disrupted protein quality control in our current study comes from the significant correlations between the heat shock proteins HSPA1A, HSP90AA1, GRYAB, HSP90AB1 and cognitive scores (Table 2).
The question arises as to what type of mechanism could account for the significant correlations between multiple salivary proteins and cognitive scores in $\mathrm{HIV}^{+}$heroin addicts. During analysis of the salivary protein dataset, we observed that many of the identified proteins are common exosomal markers, for example, the heat shock protein HSP90AAl is one of the most common exosomal markers in the ExoCarta database [73]. Exosomes are 30-100 nm membrane vesicles of endocytic origin released from multivesicular bodies into the extracellular environment by most cells [73]. Proteomic studies have shown that certain proteins are common to all exosomes, including chaperones and cytoskeletal proteins, regardless of their cell of origin, while other exosomal proteins are cell-type specific [74]. In addition to protein, exosomes contain mRNA and miRNA that can be shuttled from one cell to another, altering gene expression in the receiving cell [75]. Of note, the
A.
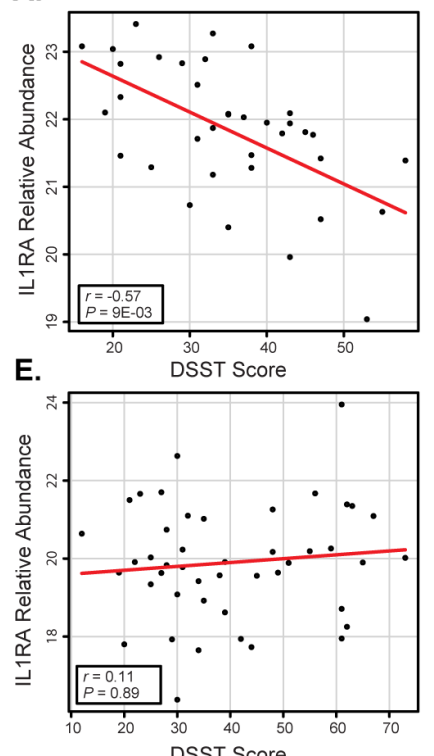

B.
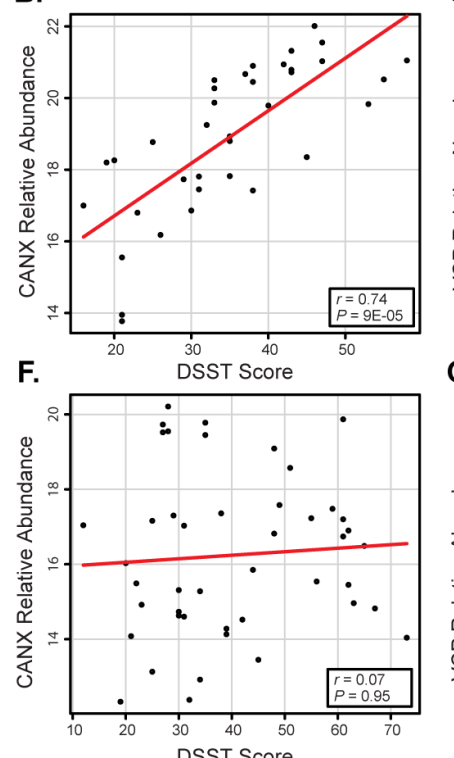

c.

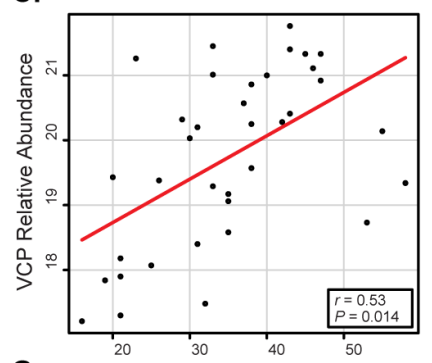

G.

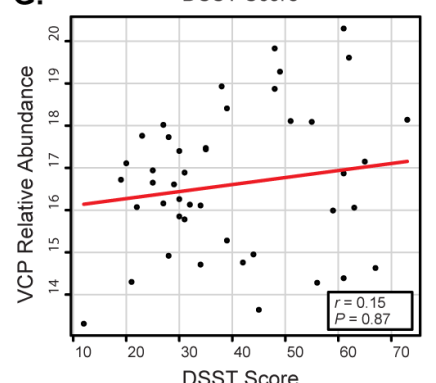

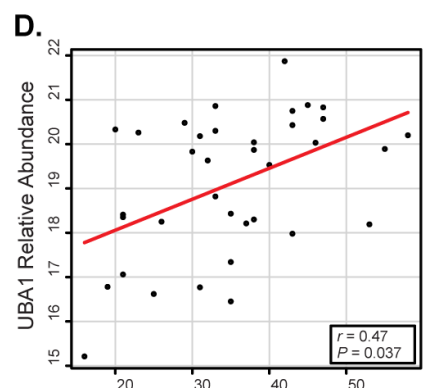

H.

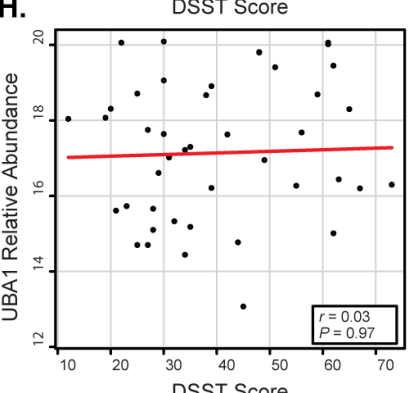

Figure 2. Differences in $\mathrm{HIV}^{+}$vs. HIV ${ }^{-}$scatter plots of DSST/protein abundance correlation analyses results for four salivary proteins of interest. (A-D) Scatter plots showing the correlation of specific salivary protein abundance values against measured DSST scores in $\mathrm{HIV}^{+}$, heroin dependent individuals. The proteins include IL1RA (interleukin-1 receptor antagonist), CANX (calnexin), VCP (valosin-containing protein), and UBA1 (ubiquitin-like modifier-activating enzyme 1). All proteins, except for IL1RA, show significant direct correlation of DSST with salivary protein abundance at $P$-value $<0.05$. (E-H) Scatter plots showing the same comparison except against $\mathrm{HIV}^{-}$heroin dependent individuals; however, no perceived correlation is observed, i.e., all p-values are well above 0.05 . The linear regression is shown by a red line, and the Pearson product-moment correlation score $(r)$ and Benjamini-Hochberg corrected $P$-values are indicated in the inlay boxes.

doi:10.1371/journal.pone.0089366.g002 


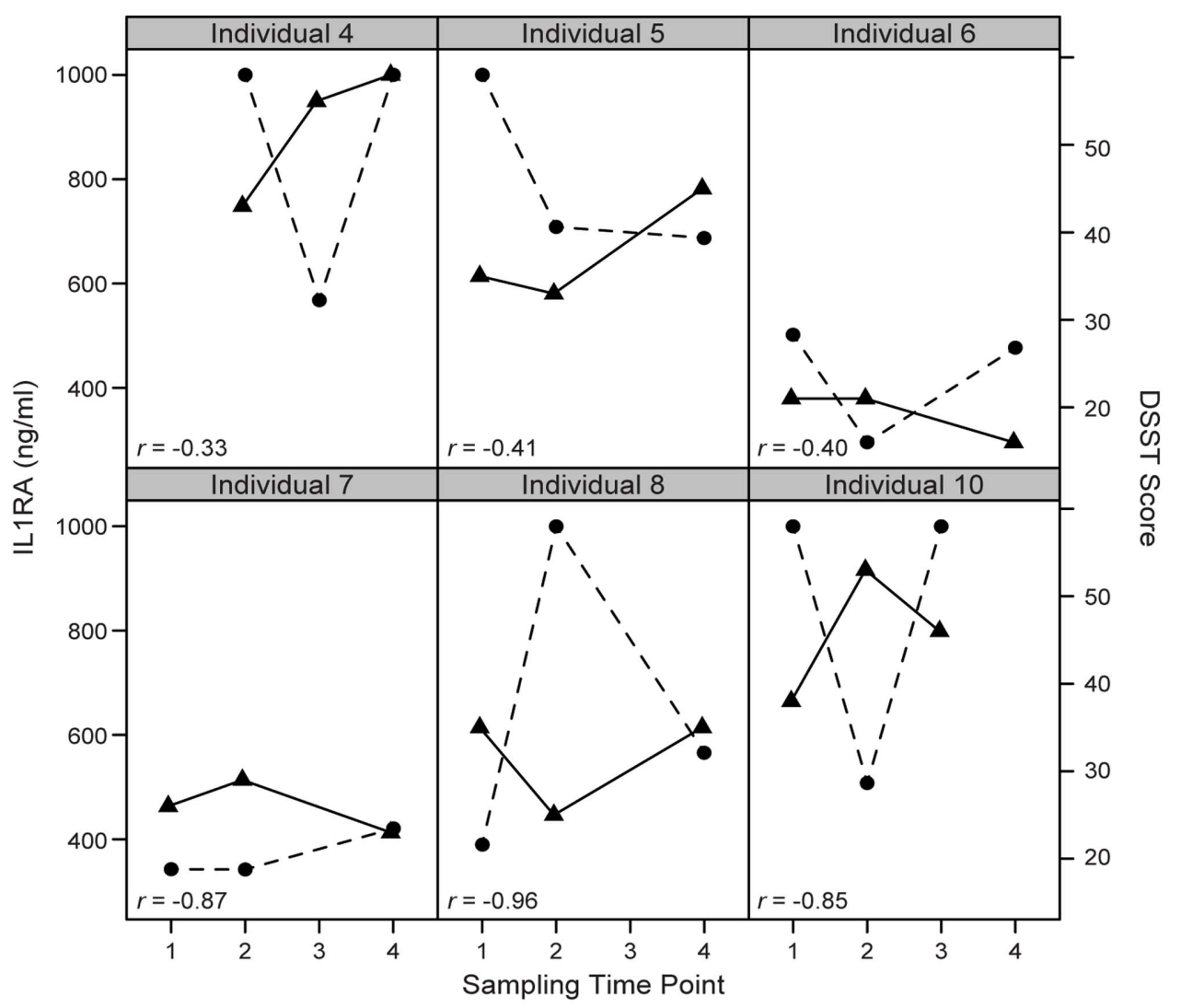

Figure 3. Inverse relationship of IL1RA ELISA results with DSST scores. Scatter plot of IL1RA ELISA absolute concentrations (circles and dotted lines) and DSST scores (triangles and solid lines) over time across 6 HIV-positive individuals showing consistent inverse correlation. Sampling time points include 1 (the day participant presents to the methadone clinic and begins first dose), 2 and 3 (second and third sessions $\sim 35$ and 36 days of methadone, respectively), and 4 ( $\sim 100$ days on methadone). The Pearson product-moment correlation scores are shown in the lower left corner of each scatter plot.

doi:10.1371/journal.pone.0089366.g003

salivary glands produce large amounts of exosomes [76]. Of particular relevance, proteomic analysis of the salivary parotid exosome by Gonzalez-Gegne et al. revealed numerous proteins associated with neurodegenerative disorders and prion disease [74]. Recent proof-of-concept studies have demonstrated that exosomes originating in the periphery can cross the blood brain barrier and influence neuronal functions [77,78]. Zhuang et al. have suggested that exosomes from the periphery may play a role in brain function [77].

\section{HIV and the Trojan Exosome Hypothesis}

The possible role of exosomes in HIV disease was first proposed by Gould et al. in 2003 [79]. Gould's group hypothesized that HIV, and other retroviruses, use the preexisting cellular exosome biogenesis pathway to form infectious exosomes that can be taken up by other cells independent of Env proteins and receptors [79]. However, the hypothesis has been challenged, with evidence showing that HIV-1 can be budded from CD4+ T-lymphocytes independently of exosomes [80]. Other researchers have provided evidence that HIV virion preparations may be contaminated by cellular exosomes [81].

Recently, Narayanan et al. conducted experiments showing that HIV-1 infected cells can produce exosomes containing unique proteins and RNA molecules, but not whole virus [82]. Narayanan's team found proteomic evidence of the HIV gp160 protein in exosomes from HIV infected cells, leading them to suggest that exosomes containing gp 160 could contribute to HIV- induced neurologic damage by crossing the blood-brain barrier independent of an actual infection [82]. In addition, $\mathrm{Hu}$ et al. have shown that astrocytes treated with morphine and HIV Tat release exosomes containing miR-29b that can be taken up by neurons resulting in neuronal death [83]. In other, non-HIV related neurodegenerative diseases, evidence is accumulating that exosomes may be involved in the spread of neurotoxic proteins [84]. On the contrary, many studies indicate that exosomes serve a protective role in the nervous system, providing stress-protective proteins and other factors for trophic support of neurons during normal and pathological conditions $[84,85]$.

We therefore compared our list of salivary proteins that exhibit significant correlations with cognitive scores with the list of exosomal proteins contained in the ExoCarta database [73], and found that 48 of the 58 salivary proteins $(82 \%)$ have been identified as components of exosomes [73]. Figure 5 is a schema of the 47 salivary proteins with positive correlations, organized by function, that have been identified in exosomes. IL1RA, the only salivary protein in our data set to exhibit a significant negative correlation with cognitive scores, has also been identified in exosomes [73].

Interestingly, several proteins involved in neuronal protection and regeneration appear in our dataset, including LGALS3 (neuronal migration and axon branching [86,87]), FLNA (neuronal migration [88]), and TUBB3 (neuronal migration [89] [90]). Glutamine synthetase (also known as glutamate-ammonia ligase), which protects the central nervous system by detoxifying 
A. HIV+ Methadone Treated

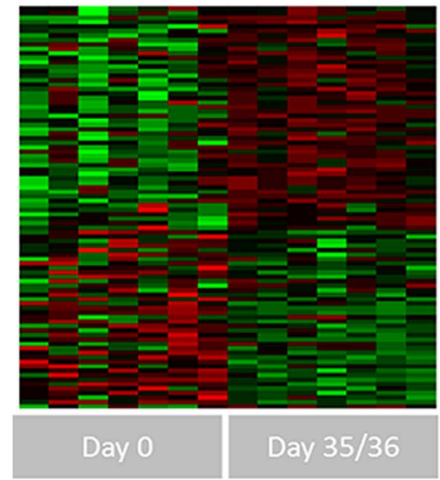

B. HIV- Methadone Treated

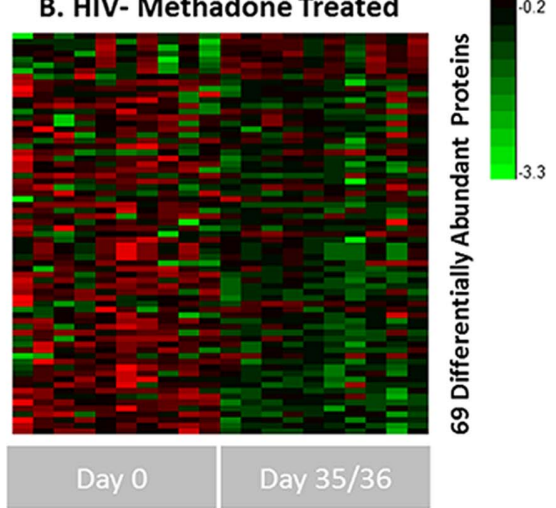

C. Overlapping Saliva Proteins

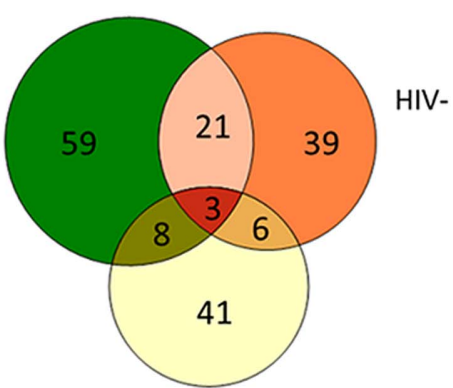

58 DSST Correlating Proteins

Figure 4. Overview of differentially abundant saliva proteins across methadone treatment. A) and B) Heat map of all differential protein abundances in the $\mathrm{HIV}^{+}$and $\mathrm{HIV}^{-}$, heroin dependent cohorts respectively due to methadone treatment (see supplemental table 3 for complete list) at $\mathrm{p}$ value $<0.05$. Clustering is based upon a Pearson distance metric with K-means clustering (K:5). Protein abundance values were scaled for plotting. C) Venn diagram showing the overlap between the respective $\mathrm{HIV}^{+/-}$heat map results and the previous 58 DSST correlating saliva proteins. doi:10.1371/journal.pone.0089366.g004

glutamate [91], also appears in our list of salivary proteins that have been identified in exosomes. Of note, the beta and delta hemoglobin chains, commonly found in exosomes [73], show a significant positive correlation with cognitive scores. The hemoglobin beta and delta chains have been shown to give rise to peptides involved in enhancing learning and memory [92]. Thus, we suggest that a possible mechanism explaining our current findings may be the existence of a pathway connecting salivary proteins to cognitive function through the shuttle of salivary exosomes to the central nervous system.

Exosomes released by one cell have been shown to influence the response of another cell to an external stress by providing the recipient cell with resistance to the external stressor [93]. Eldh et al. have shown that exosomes released by cells exposed to a stressor, for example oxidative stress, can mediate a protective signal to another cell, making the recipient cell more tolerant to an oxidative process and subsequent cell death [93]. Accordingly, the salivary glands are known to be impacted by HIV disease [94], and therefore salivary gland cells are likely to be exposed to HIVinduced proteolytic stress. We therefore propose that salivary gland cells may be capable of releasing exosomes containing protein and RNA that can mediate a tolerizing effect to proteolytic stress in distant cells, including brain cells. Exosomes were recently identified in human CSF [95], and further research will be needed to explore the possibility that salivary exosomes contribute to the CSF exosome pool.
Our finding that salivary IL1RA has a significant negative correlation with cognitive scores in $\mathrm{HIV}^{+}$subjects seems counterintuitive, as the deleterious role of IL-1 in the central nervous system has been firmly established in experimental models $[63,96]$. However, Rimaniol et al. have demonstrated an imbalance between IL-1 and IL1RA in the CSF of $\mathrm{HIV}^{+}$patients, noting high IL1RA concentrations, but undetectable levels of IL-1 [97]. Thus, our data showing a significant negative correlation of salivary IL1RA with cognition may be a reflection of elevated IL1RA levels in the CSF of $\mathrm{HIV}^{+}$subjects. Since blood-borne IL1RA has been shown to cross the blood-brain barrier [98,99], it is plausible that salivary IL1RA may translocate from the oral cavity to the brain during HIV infection to add to the imbalance between IL1RA and IL-1 and disrupt protein homeostasis. Transgenic mice over-expressing IL1RA in the brain have been shown to have impairments in the formation of long-term hippocampal-dependent memory [100,101], and IL1RA protein aggregates have been identified in Alzheimer's disease plaques and tangles, and in the temporal cortex of patients with frontotemporal lobe dementia [102]. Wang et al. have suggested that the basal activity of the IL-1 receptor regulates the normal function of the ubiquitin-proteasome system and autophagy, and that elevated IL1RA activity could lead to the accumulation of misfolded proteins [103]. Thus, the proteins we identified that are involved in protein quality control, and that have positive correlations with cognitive scores, such as VCP, UBAl, and CANX, may represent a protective response to IL1RA-induced disruption of proteolysis. 


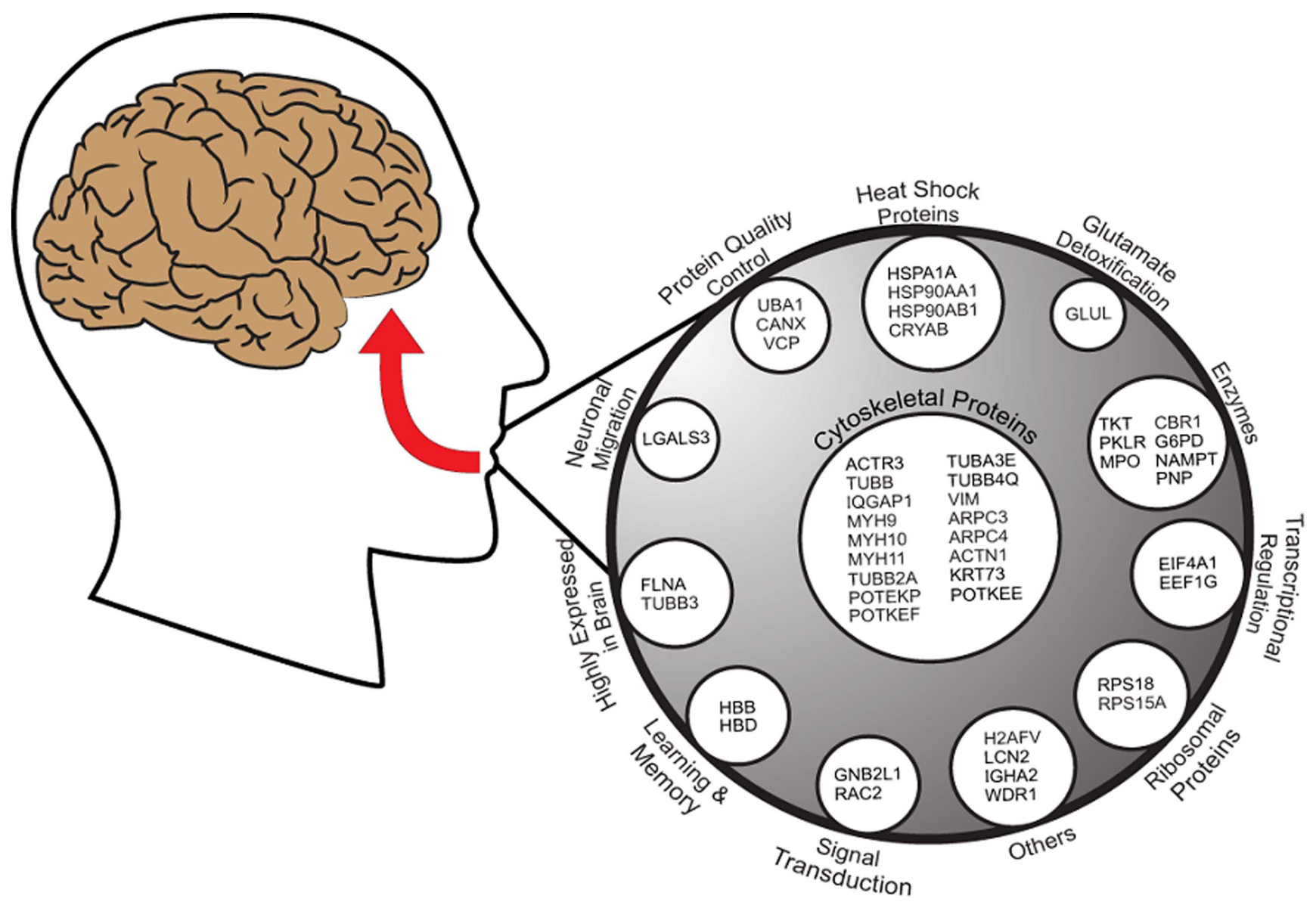

Figure 5. A graphical representation of the overlap between 47 salivary proteins that demonstrated significant positive correlations with DSST scores in HIV $^{+}$heroin addicts and exosomal proteins identified in the ExoCarta database [73]. Proteins are grouped by functional categories for visualization purposes, and not sub-exosomal localization. Adapted from Mathivanin et al. [105]. doi:10.1371/journal.pone.0089366.g005

This hypothesis is consistent with the concept that defective protein quality control underlies HAND pathogenesis [72].

Limits of this study include the fact that all of the $\mathrm{HIV}^{+}$subjects, except one, had a history of exposure to antiretroviral medications or were taking cART at the time of the study (Table 1). Therefore, we cannot say for certain that the observed proteomic and cognitive results are due solely to HIV-infection. Evaluation of the salivary proteome and cognitive scores in the $\mathrm{HIV}^{+}$group does not distinguish patterns that may be due to cART exposure from those that are associated solely with chronic HIV infection. Future studies are required to decouple viral infection from cART in influencing proteomic and cognitive results. In addition, the HIV ${ }^{-}$ group was using significantly more methamphetamine/amphetamine than the $\mathrm{HIV}^{+}$group (Table 1). Methamphetamine is known to cause proteasome inhibition and disruption of protein homeostasis [104], so it is possible that any correlations that might exist between salivary proteins and cognitive scores in the HIV ${ }^{-}$ heroin users is disrupted by methamphetamine use. This could also possibly explain the more heterogenous nature of the HIV group in terms of methadone treatment response. We recognize a need to determine if $\mathrm{HIV}^{+}$, non-drug addicted subjects demonstrate significant correlations between salivary proteins and cognitive scores, however considering that $\mathrm{HIV}^{-}$, non-drug addicted subjects do not demonstrate saliva proteome DSST correlations, this leads us to believe that HIV is at least a major contributing factor to this result, and to what extent the additional stresses of drug abuse/treatment play a contributing role is yet to be determined, but presents avenues of further investigation. Lastly, our $\mathrm{HIV}^{+}$group contained only males, which may have also contributed to the more homogeneous nature of the $\mathrm{HIV}^{+}$ group; however, limiting the $\mathrm{HIV}^{-}$, heroin-addicted group to only males (6) did not noticeably reduce the heterogeneity in methadone treatment responses (data not shown), so we doubt that gender was a major contributing factor. There is a need to determine if $\mathrm{HIV}^{+}$, heroin-addicted and non-drug addicted females demonstrate correlations between salivary proteins and cognition.

In conclusion, we have identified 58 salivary proteins that demonstrate significant correlations with cognitive scores in $\mathrm{HIV}^{+}$ heroin addicts, with only one protein, ILlRA, showing a negative correlation. These results were not found in $\mathrm{HIV}^{-}$heroin addicts, or $\mathrm{HIV}^{-}$non-addicts. A subset of these proteins appears sensitive to methadone treatment but the majority was independent of treatment. We propose a novel hypothesis that discrete packets of salivary proteins in the form of exosomes may be produced by the salivary glands and/or oral epithelium in response to HIV infection, and that these exosomes are capable of modulating brain function. Since exosomes were recently discovered in human cerebrospinal fluid (CSF) [95], it may be possible to design experiments to determine if salivary exosomes contribute to the CSF exosome pool. Furthermore, we propose that IL1RA, originating in the oral cavity, may translocate to the brain during 
HIV infection, disrupt protein homeostasis, and contribute to the pathogenesis of HAND. More research needs to be carried out to test these novel hypotheses.

\section{Supporting Information}

Table S1 Table of measured DSST scores for each participant and time point.

(PDF)

Table S2 List of peptide identifications and corresponding mass spectrometry metrics, probability values, and quantitative information for each analysis which support the reported protein identification and quantification.

(XLSX)

Table S3 List of protein identifications and quantitative information for each analysis. (XLSX)

Table S4 List of specific salivary proteins from our current study that correlate with DSST scores that overlap with proteins that are previously shown to be modulated by morphine and other drugs of abuse.

(PDF)

\section{References}

1. Heaton RK, Franklin DR, Ellis RJ, McCutchan JA, Letendre SL, et al. (2011) $\mathrm{HIV}$-associated neurocognitive disorders before and during the era of combination antiretroviral therapy: differences in rates, nature, and predictors. J Neurovirol 17: 3-16.

2. Spudich S, Gisslen M, Hagberg L, Lee E, Liegler T, et al. (2011) Central nervous system immune activation characterizes primary human immunodeficiency virus 1 infection even in participants with minimal cerebrospinal fluid viral burden. J Infect Dis 204: 753-760.

3. Bell JE, Arango JC, Anthony IC (2006) Neurobiology of multiple insults: HIV1 -associated brain disorders in those who use illicit drugs. J Neuroimmune Pharmacol 1: 182-191.

4. Diamond B, Huerta PT, Tracey K, Volpe BT (2011) It takes guts to grow a brain: Increasing evidence of the important role of the intestinal microflora in neuro- and immune-modulatory functions during development and adulthood. Bioessays 33: 588-591.

5. Collins SM, Surette M, Bercik P (2012) The interplay between the intestinal microbiota and the brain. Nat Rev Microbiol 10: 735-742.

6. Cryan JF, Dinan TG (2012) Mind-altering microorganisms: the impact of the gut microbiota on brain and behaviour. Nat Rev Neurosci 13: 701-712.

7. Cockburn AF, Dehlin JM, Ngan T, Crout R, Boskovic G, et al. (2012) High throughput DNA sequencing to detect differences in the subgingival plaque microbiome in elderly subjects with and without dementia. Investig Genet 3: 19.

8. Nam JW, Chung JW, Kho HS, Chung SC, Kim YK (2007) Nerve growth factor concentration in human saliva. Oral Dis 13: 187-192.

9. Devic I, Hwang H, Edgar JS, Izutsu K, Presland R, et al. (2011) Salivary alphasynuclein and DJ-1: potential biomarkers for Parkinson's disease. Brain 134: e178.

10. Oh YS, Turner RJ (2006) Effect of gamma-secretase inhibitors on muscarinic receptor-mediated calcium signaling in human salivary epithelial cells. Am J Physiol Cell Physiol 291: C76-82.

11. Bermejo-Pareja F, Antequera D, Vargas T, Molina JA, Carro E (2010) Saliva levels of Abeta 1-42 as potential biomarker of Alzheimer's disease: a pilot study. BMC Neurol 10: 108 .

12. Shi M, Sui YT, Peskind ER, Li G, Hwang H, et al. (2011) Salivary tau species are potential biomarkers of Alzheimer's disease. J Alzheimers Dis 27: 299-305.

13. Rozek W, Ricardo-Dukelow M, Holloway S, Gendelman HE, Wojna V, et al. (2007) Cerebrospinal fluid proteomic profiling of HIV-1-infected patients with cognitive impairment. J Proteome Res 6: 4189-4199.

14. Laspiur JP, Anderson ER, Ciborowski P, Wojna V, Rozek W, et al. (2007) CSF proteomic fingerprints for HIV-associated cognitive impairment. J Neuroimmunol 192: 157-170.
Table S5 List of specific salivary proteins with correlations with DSST scores and proteins identified in prior proteomic studies related to HIV infection.

(PDF)

Table S6 List of 91 and 69 proteins from HIV+ and HIVparticipants respectively with significant differential abundance at 35/36 days of methadone treatment. (XLSX)

\section{Acknowledgments}

Special thanks to Elizabeth Sinclair and Ross Okamura for assistance with the IL1RA ELISA research portion. The collection of saliva samples followed guidelines established by the UCSF institutional review board. Research was performed in the Environmental Molecular Science Laboratory, a U.S. Department of Energy (DOE) national scientific user facility at Pacific Northwest National Laboratory (PNNL) in Richland, WA. Battelle operates PNNL for the DOE under contract DE-AC0576RLO01830.

\section{Author Contributions}

Conceived and designed the experiments: SSD JNB JMJ. Performed the experiments: JNB MG. Analyzed the data: JNB SSD JMJ. Contributed reagents/materials/analysis tools: SSD RDS. Wrote the paper: SSD JNB JMJ MIR MG RDS.

15. Wiederin J, Rozek W, Duan F, Ciborowski P (2009) Biomarkers of HIV-1 associated dementia: proteomic investigation of sera. Proteome Sci 7: 8.

16. Rozek W, Horning J, Anderson J, Ciborowski P (2008) Sera proteomic biomarker profiling in HIV-1 infected subjects with cognitive impairment. Proteomics Clin Appl 2: 1498-1507.

17. Toro-Nieves DM, Rodriguez Y, Plaud M, Ciborowski P, Duan F, et al. (2009) Proteomic analyses of monocyte-derived macrophages infected with human immunodeficiency virus type 1 primary isolates from Hispanic women with and without cognitive impairment. J Neurovirol 15: 36-50.

18. Zhou L, Diefenbach E, Crossett B, Tran SL, Ng T, et al. (2010) First evidence of overlaps between HIV-Associated Dementia (HAD) and non-viral neurodegenerative diseases: proteomic analysis of the frontal cortex from HIV+ patients with and without dementia. Mol Neurodegener 5: 27.

19. Gelman BB, Nguyen TP (2010) Synaptic proteins linked to HIV-1 infection and immunoproteasome induction: proteomic analysis of human synaptosomes. J Neuroimmune Pharmacol 5: 92-102

20. Stockton SD, Jr., Devi LA (2014) An integrated quantitative proteomics and systems biology approach to explore synaptic protein profile changes during morphine exposure. Neuropsychopharmacology 39: 88-103.

21. Wang J, Yuan W, Li MD (2011) Genes and pathways co-associated with the exposure to multiple drugs of abuse, including alcohol, amphetamine/ methamphetamine, cocaine, marijuana, morphine, and/or nicotine: a review of proteomics analyses. Mol Neurobiol 44: 269-286.

22. Brown JN, Ortiz GM, Angel TE, Jacobs JM, Gritsenko M, et al. (2012) Morphine produces immunosuppressive effects in nonhuman primates at the proteomic and cellular levels. Mol Cell Proteomics 11: 605-618.

23. Zill P, Vielsmeier V, Buttner A, Eisenmenger W, Siedler F, et al (2011) Postmortem proteomic analysis in human amygdala of drug addicts: possible impact of tubulin on drug-abusing behavior. Eur Arch Psychiatry Clin Neurosci 261: 121-131.

24. Byrd DA, Robinson-Papp J, Mindt MR, Mintz L, Elliott K, et al. (2013) Isolating cognitive and neurologic HIV effects in substance-dependent, confounded cohorts: a pilot study. J Int Neuropsychol Soc 19: 463-473.

25. Yuan K, Qin W, Dong M, Liu J, Sun J, et al. (2010) Gray matter deficits and resting-state abnormalities in abstinent heroin-dependent individuals. Neurosci Lett 482: 101-105.

26. Yuan Y, Zhu Z, Shi J, Zou Z, Yuan F, et al. (2009) Gray matter density negatively correlates with duration of heroin use in young lifetime heroindependent individuals. Brain Cogn 71: 223-228.

27. Denier N, Schmidt A, Gerber H, Schmid O, Riecher-Rossler A, et al. (2013) Association of frontal gray matter volume and cerebral perfusion in heroin addiction: a multimodal neuroimaging study. Front Psychiatry 4: 135 
28. Cheng GL, Zeng H, Leung MK, Zhang HJ, Lau BW, et al. (2013) Heroin abuse accelerates biological aging: a novel insight from telomerase and brain imaging interaction. Transl Psychiatry 3: e260.

29. Mintzer MZ, Stitzer ML (2002) Cognitive impairment in methadone maintenance patients. Drug Alcohol Depend 67: 41-51.

30. Verdejo A, Toribio I, Orozco C, Puente KL, Perez-Garcia M (2005) Neuropsychological functioning in methadone maintenance patients versus abstinent heroin abusers. Drug Alcohol Depend 78: 283-288.

31. Darke S, McDonald S, Kaye S, Torok M (2012) Comparative patterns of cognitive performance amongst opioid maintenance patients, abstinent opioid users and non-opioid users. Drug Alcohol Depend 126: 309-315.

32. Salthouse TA (1992) What do adult age differences in the Digit Symbol Substitution Test reflect? J Gerontol 47: P121-128.

33. Becker JT, Salthouse TA (1999) Neuropsychological test performance in the acquired immunodeficiency syndrome: independent effects of diagnostic group on functioning. J Int Neuropsychol Soc 5: 41-47.

34. Gruber VA, Rainey PM, Moody DE, Morse GD, Ma Q et al. (2012) Interactions between buprenorphine and the protease inhibitors darunavirritonavir and fosamprenavir-ritonavir. Clin Infect Dis 54: 414-423.

35. McLeod DR, Griffiths RR, Bigelow GE, Yingling J (1982) An automated version of the digit symbol substitution test (DSST). Behavior Research Methods and Instrumentation 14: 463-466.

36. Rosano G, Newman AB, Katz R, Hirsch CH, Kuller LH (2008) Association between lower digit symbol substitution test score and slower gait and greater risk of mortality and of developing incident disability in well-functioning older adults. J Am Geriatr Soc 56: 1618-1625.

37. Marginean I, Kelly RT, Moore RJ, Prior DC, LaMarche BL, et al. (2009) Selection of the optimum electrospray voltage for gradient elution LC-MS measurements. J Am Soc Mass Spectrom 20: 682-688.

38. Kelly RT, Page JS, Zhao R, Qian WJ, Mottaz HM, et al. (2008) Capillarybased multi nanoelectrospray emitters: improvements in ion transmission efficiency and implementation with capillary reversed-phase LC-ESI-MS. Anal Chem 80: 143-149.

39. Page JS, Kelly RT, Tang K, Smith RD (2007) Ionization and transmission efficiency in an electrospray ionization-mass spectrometry interface. J Am Soc Mass Spectrom 18: 1582-1590.

40. Jaitly N, Monroe ME, Petyuk VA, Clauss TR, Adkins JN, et al. (2006) Robust algorithm for alignment of liquid chromatography-mass spectrometry analyses in an accurate mass and time tag data analysis pipeline. Anal Chem 78: 73977409.

41. Kiebel GR, Auberry KJ, Jaitly N, Clark DA, Monroe ME, et al. (2006) PRISM: a data management system for high-throughput proteomics. Proteomics 6: 1783-1790.

42. Monroe ME, Tolic N, Jaitly N, Shaw JL, Adkins JN, et al. (2007) VIPER: an advanced software package to support high-throughput LC-MS peptide identification. Bioinformatics 23: 2021-2023.

43. Monroe ME, Shaw JL, Daly DS, Adkins JN, Smith RD (2008) MASIC: a software program for fast quantitation and flexible visualization of chromatographic profiles from detected LC-MS(/MS) features. Comput Biol Chem 32: 215-217.

44. Petritis K, Kangas LJ, Yan B, Monroe ME, Strittmatter EF, et al. (2006) Improved peptide elution time prediction for reversed-phase liquid chromatography-MS by incorporating peptide sequence information. Anal Chem 78: 5026-5039.

45. Stanley JR, Adkins JN, Slysz GW, Monroe ME, Purvine SO, et al. (2011) A statistical method for assessing Peptide identification confidence in accurate mass and time tag proteomics. Anal Chem 83: 6135-6140.

46. Kim S, Gupta N, Pevzner PA (2008) Spectral probabilities and generating functions of tandem mass spectra: a strike against decoy databases. J Proteome Res 7: 3354-3363.

47. Team RDC (2008) R: A language and environment for statistical computing. Vienna, Austria: R Foundation for Statistical Computing.

48. Taverner T, Karpievitch YV, Polpitiya AD, Brown JN, Dabney AR, et al. (2012) DanteR: an extensible R-based tool for quantitative analysis of-omics data. Bioinformatics.

49. Matzke MM, Brown JN, Gritsenko MA, Metz TO, Pounds JG, et al. (2013) A comparative analysis of computational approaches to relative protein quantification using peptide peak intensities in label-free LC-MS proteomics experiments. Proteomics 13: 493-503.

50. Benjamini Y, Hochberg Y (1995) Controlling the False Discovery Rate - a Practical and Powerful Approach to Multiple Testing. Journal of the Royal Statistical Society Series B-Methodological 57: 289-300.

51. Weihl CC (2011) Valosin containing protein associated fronto-temporal lobar degeneration: clinical presentation, pathologic features and pathogenesis. Curr Alzheimer Res 8: 252-260.

52. Yamanaka K, Sasagawa Y, Ogura T (2012) Recent advances in p97/VCP/ Cdc48 cellular functions. Biochim Biophys Acta 1823: 130-137.

53. Taylor EB, Rutter J (2011) Mitochondrial quality control by the ubiquitinproteasome system. Biochem Soc Trans 39: 1509-1513.

54. Watts GD, Wymer J, Kovach MJ, Mehta SG, Mumm S, et al. (2004) Inclusion body myopathy associated with Paget disease of bone and frontotemporal dementia is caused by mutant valosin-containing protein. Nat Genet 36: 377 381.
55. Dolan PJ, Jin YN, Hwang W, Johnson GV (2011) Decreases in valosincontaining protein result in increased levels of tau phosphorylated at Ser262/ 356. FEBS Lett 585: 3424-3429.

56. Jager S, Cimermancic P, Gulbahce N, Johnson JR, McGovern KE, et al. (2012) Global landscape of HIV-human protein complexes. Nature 481: 365-370.

57. Ciechanover A, Brundin P (2003) The ubiquitin proteasome system in neurodegenerative diseases: sometimes the chicken, sometimes the egg. Neuron 40: $427-446$.

58. Ramser J, Ahearn ME, Lenski C, Yariz KO, Hellebrand H, et al. (2008) Rare missense and synonymous variants in UBE1 are associated with $\mathrm{X}$-linked infantile spinal muscular atrophy. Am J Hum Genet 82: 188-193.

59. Ou WJ, Cameron PH, Thomas DY, Bergeron JJ (1993) Association of folding intermediates of glycoproteins with calnexin during protein maturation. Nature 364: $771-776$.

60. Sitia R, Braakman I (2003) Quality control in the endoplasmic reticulum protein factory. Nature 426: 891-894.

61. Wang W, Chen R, Luo K, Wu D, Huang L, et al. (2010) Calnexin inhibits thermal aggregation and neurotoxicity of prion protein. J Cell Biochem 111: 343-349.

62. Papandreou MJ, Barbouche R, Guieu R, Rivera S, Fantini J, et al. (2010) Mapping of domains on HIV envelope protein mediating association with calnexin and protein-disulfide isomerase. J Biol Chem 285: 13788-13796.

63. Spulber S, Bartfai T, Schultzberg M (2009) IL-1/IL-1ra balance in the brain revisited - evidence from transgenic mouse models. Brain Behav Immun 23: 573-579.

64. Zavala F, Rimaniol AC, Boussin F, Dormont D, Bach JF, et al. (1995) HIV predominantly induces IL-1 receptor antagonist over IL-1 synthesis in human primary monocytes. J Immunol 155: 2784-2793.

65. Jackrel ME, Shorter J (2011) Shock and awe: unleashing the heat shock response to treat Huntington disease. J Clin Invest 121: 2972-2975.

66. Johnson JL (2011) Evolution and function of diverse Hsp90 homologs and cochaperone proteins. Biochim Biophys Acta.

67. Theodoraki MA, Caplan AJ (2011) Quality control and fate determination of Hsp90 client proteins. Biochim Biophys Acta.

68. Jarosz DF, Lindquist S (2010) Hsp90 and environmental stress transform the adaptive value of natural genetic variation. Science 330: 1820-1824.

69. Ojha J, Karmegam RV, Masilamoni JG, Terry AV, Cashikar AG (2011) Behavioral defects in chaperone-deficient Alzheimer's disease model mice. PLoS One 6: e16550.

70. Taipale M, Jarosz DF, Lindquist S (2010) HSP90 at the hub of protein homeostasis: emerging mechanistic insights. Nat Rev Mol Cell Biol 11: 515528.

71. Proctor CJ, Lorimer IA (2011) Modelling the role of the Hsp70/Hsp90 system in the maintenance of protein homeostasis. PLoS One 6: e22038.

72. Kragh CL, Ubhi K, Wyss-Corey T, Masliah E (2012) Autophagy in dementias. Brain Pathol 22: 99-109.

73. Mathivanan S, Simpson RJ (2009) ExoCarta: A compendium of exosomal proteins and RNA. Proteomics 9: 4997-5000.

74. Gonzalez-Begne M, Lu B, Han X, Hagen FK, Hand AR, et al. (2009) Proteomic analysis of human parotid gland exosomes by multidimensional protein identification technology (MudPIT). J Proteome Res 8: 1304-1314.

75. Palanisamy V, Sharma S, Deshpande A, Zhou H, Gimzewski J, et al. (2010) Nanostructural and transcriptomic analyses of human saliva derived exosomes. PLoS One 5: e8577.

76. Kapsogeorgou EK, Abu-Helu RF, Moutsopoulos HM, Manoussakis MN (2005) Salivary gland epithelial cell exosomes: A source of autoantigenic ribonucleoproteins. Arthritis Rheum 52: 1517-1521.

77. Zhuang X, Xiang X, Grizzle W, Sun D, Zhang S, et al. (2011) Treatment of brain inflammatory diseases by delivering exosome encapsulated antiinflammatory drugs from the nasal region to the brain. Mol Ther 19: 17691779 .

78. Alvarez-Erviti L, Seow Y, Yin H, Betts C, Lakhal S, et al. (2011) Delivery of siRNA to the mouse brain by systemic injection of targeted exosomes. Nat Biotechnol 29: 341-345.

79. Gould SJ, Booth AM, Hildreth JE (2003) The Trojan exosome hypothesis. Proc Natl Acad Sci U S A 100: 10592-10597.

80. Park IW, He JJ (2010) HIV-1 is budded from CD4+ T lymphocytes independently of exosomes. Virol J 7: 234.

81. Coren LV, Shatzer T, Ott DE (2008) CD45 immunoaffinity depletion of vesicles from Jurkat $\mathrm{T}$ cells demonstrates that exosomes contain CD45: no evidence for a distinct exosome/HIV-1 budding pathway. Retrovirology 5: 64 .

82. Narayanan A, Iordanskiy S, Das R, Van Duyne R, Santos S, et al. (2013) Exosomes derived from HIV-1-infected cells contain trans-activation response element RNA. J Biol Chem 288: 20014-20033.

83. Hu G, Yao H, Chaudhuri AD, Duan M, Yelamanchili SV, et al. (2012) Exosome-mediated shuttling of microRNA-29 regulates HIV Tat and morphine-mediated neuronal dysfunction. Cell Death Dis 3: e381.

84. Lai CP, Breakefield XO (2012) Role of exosomes/microvesicles in the nervous system and use in emerging therapies. Front Physiol 3: 228.

85. Williams JL, Gatson NN, Smith KM, Almad A, McTigue DM, et al. (2013) Serum exosomes in pregnancy-associated immune modulation and neuroprotection during CNS autoimmunity. Clin Immunol 149: 236-243. 
86. Comte I, Kim Y, Young CC, van der Harg JM, Hockberger P, et al. (2011) Galectin-3 maintains cell motility from the subventricular zone to the olfactory bulb. J Cell Sci 124: 2438-2447.

87. Diez-Revuelta N, Velasco S, Andre S, Kaltner H, Kubler D, et al. (2010) Phosphorylation of adhesion- and growth-regulatory human galectin-3 leads to the induction of axonal branching by local membrane L1 and ERM redistribution. J Cell Sci 123: 671-681.

88. Sheen VL, Feng Y, Graham D, Takafuta T, Shapiro SS, et al. (2002) Filamin A and Filamin $\mathrm{B}$ are co-expressed within neurons during periods of neuronal migration and can physically interact. Hum Mol Genet 11: 2845-2854.

89. Tischfield MA, Baris HN, Wu C, Rudolph G, Van Maldergem L, et al. (2010) Human TUBB3 mutations perturb microtubule dynamics, kinesin interactions, and axon guidance. Cell 140: 74-87.

90. Tischfield MA, Cederquist GY, Gupta ML, Jr., Engle EC (2011) Phenotypic spectrum of the tubulin-related disorders and functional implications of diseasecausing mutations. Curr Opin Genet Dev 21: 286-294.

91. Fernandes SP, Dringen R, Lawen A, Robinson SR (2010) Neurones express glutamine synthetase when deprived of glutamine or interaction with astrocytes. J Neurochem 114: 1527-1536.

92. Gomes I, Dale CS, Casten K, Geigner MA, Gozzo FC, et al. (2010) Hemoglobin-derived peptides as novel type of bioactive signaling molecules. AAPS J 12: 658-669.

93. Eldh M, Ekstrom K, Valadi H, Sjostrand M, Olsson B, et al. (2010) Exosomes communicate protective messages during oxidative stress; possible role of exosomal shuttle RNA. PLoS One 5: e15353.

94. Jeffers L, Webster-Cyriaque JY (2011) Viruses and salivary gland disease (SGD): lessons from HIV SGD. Adv Dent Res 23: 79-83.

95. Street JM, Barran PE, Mackay CL, Weidt S, Balmforth C, et al. (2012) Identification and proteomic profiling of exosomes in human cerebrospinal fluid. J Transl Med 10: 5.

96. Goshen I, Kreisel T, Ben-Menachem-Zidon O, Licht T, Weidenfeld J, et al. (2008) Brain interleukin-1 mediates chronic stress-induced depression in mice via adrenocortical activation and hippocampal neurogenesis suppression. Mol Psychiatry 13: 717-728.

97. Rimaniol AC, Zylberberg H, Rabian C, DeGroote D, Zavala F, et al. (1997) Imbalance between IL-1 and IL-1 receptor antagonist in the cerebrospinal fluid of HIV-infected patients. J Acquir Immune Defic Syndr Hum Retrovirol 16: 340-342.

98. Gutierrez EG, Banks WA, Kastin AJ (1994) Blood-borne interleukin-1 receptor antagonist crosses the blood-brain barrier. J Neuroimmunol 55: 153-160.

99. Galea J, Ogungbenro K, Hulme S, Greenhalgh A, Aarons L, et al. (2011) Intravenous anakinra can achieve experimentally effective concentrations in the central nervous system within a therapeutic time window: results of a doseranging study. J Cereb Blood Flow Metab 31: 439-447.

100. Goshen I, Kreisel T, Ounallah-Saad H, Renbaum P, Zalzstein Y, et al. (2007) A dual role for interleukin-1 in hippocampal-dependent memory processes. Psychoneuroendocrinology 32: 1106-1115.

101. Spulber S, Mateos L, Oprica M, Cedazo-Minguez A, Bartfai T, et al. (2009) Impaired long term memory consolidation in transgenic mice overexpressing the human soluble form of IL-1ra in the brain. J Neuroimmunol 208: 46-53.

102. Yasuhara O, Matsuo A, Terai K, Walker DG, Berger AE, et al. (1997) Expression of interleukin-1 receptor antagonist protein in post-mortem human brain tissues of Alzheimer's disease and control cases. Acta Neuropathol 93: $414-420$

103. Wang CE, Li S, Li XJ (2010) Lack of interleukin-1 type 1 receptor enhances the accumulation of mutant huntingtin in the striatum and exacerbates the neurological phenotypes of Huntington's disease mice. Mol Brain 3: 33.

104. Lazzeri G, Lenzi P, Gesi M, Ferrucci M, Fulceri F, et al. (2006) In PC12 cells neurotoxicity induced by methamphetamine is related to proteasome inhibition. Ann N Y Acad Sci 1074: 174-177.

105. Mathivanan S, Ji H, Simpson RJ (2010) Exosomes: extracellular organelles important in intercellular communication. J Proteomics 73: 1907-1920. 